\title{
Biodegradação de poliestireno expandido utilizando Tenebrio molitor Linnaeus, 1758 (Coleoptera: Tenebrionidae) e Zophobas morio Fabricius, 1776 (Coleoptera: Tenebrionidae)
}

\section{Amanda da Silva Medeiros, Aruani Letícia da Silva Tomoto, José Hilton Bernardino de Araújo, Gabriel da Rocha Bragion*, Beatriz Garbin, Gabriel de Melo Silva Borges Cherulli, Ivens Vinicius de Matos}

Universidade Tecnológica Federal do Paraná. Departamento Acadêmico de Ambiental. Campus Campo Mourão. Rua Rosalina Maria Ferreira, 1233. Vila Guaruja. Campo Mourão-PR, Brasil (CEP 87301-899). *E-mail: gabriel.bragion@hotmail.com.

Resumo. O plástico é considerado um dos principais resíduos causadores de grandes impactos ambientais, devido principalmente ao seu baixo custo e utilização em diversas formas, dificultando um manejo ambientalmente correto. Um novo método de degradação de um dos principais tipos de plástico, o poliestireno expandido (EPS), está sendo estudado utilizando Tenebrio molitor Linnaeus, 1758 (Coleoptera: Tenebrionidae) e Zophobas morio Fabricius, 1776 (Coleoptera: Tenebrionidae), que são capazes de digerir este polímero. 0 objetivo do presente artigo foi analisar os comportamentos das espécies T. molitor e Z. morio como agentes biodegradantes do EPS. Foram realizados testes de fome com ambas as espécies, utilizando dois grupos de controle e dois para os testes, sendo o grupo de controle alimentado com farinha e aveia integrais, batata e EPS, pesando os indivíduos e o EPS dos quatro grupos a cada sete dias. Para o teste microbiano foi retirado o conteúdo estomacal de dois indivíduos de ambas as espécies e diluídos em água destilada estéril, para inoculação em meio de cultura. A partir das colônias resultantes, foram isoladas as bactérias pelas diferentes colorações para posteriormente serem inoculadas em um meio basal livre de carbono contendo uma película de EPS previamente diluída em clorofórmio e seca ao ar livre. Como resultado, foi observado que no teste de fome após 14 dias ocorreu redução no peso do EPS para ambas as espécies, sendo $3,62 \%$ de redução para T. molitor e $3,01 \%$ para $Z$. morio. No teste microbiano, apenas uma colônia, identificada pela cor laranja, apresentou crescimento sobre a película de EPS. É possível concluir que ambas as espécies apresentaram resultados positivos de degradação do EPS, além disso a colônia bacteriana de coloração laranja encontrada no trato intestinal de ambas as espécies apresentou resultados relevantes de degradação do EPS.
Recebido:

$01 / 12 / 2017$

Aceito:

$21 / 03 / 2018$

Publicado:

$30 / 04 / 2018$

Acesso aberto

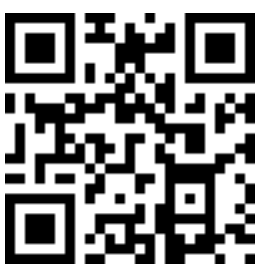

ORCID

(C) 0000-0001-9409-1502 Amanda da Silva Medeiros

(D) 0000-0003-4953-2086 Aruani Letícia da Silva Tomoto

D 0000-0001-9743-7855 José Hilton Bernardino de Araújo

(D) 0000-0003-3875-4986 Gabriel da Rocha Bragion 
Palavras-chave: Tenébrio; Tenebrio molitor; Zophobas morio; Tenébrio gigante; Isopor; Degradação de plástico.

\begin{abstract}
Biodegradation of the expanded polystyrene using Tenebrio molitor Linnaeus, 1758 (Coleoptera: Tenebrionidae) $e$ Zophobas morio Fabricius, 1776 (Coleoptera: Tenebrionidae). Plastic is considered one of the the main residue that most causes environmental impacts, due mainly to its low cost and high application, making environmentally correct management difficult. A new degradation method of one of the main plastic type, expanded polystyrene (EPS) has been studied, using Tenebrio molitor Linnaeus, 1758 (Coleoptera: Tenebrionidae) and Zophobas morio Fabricius, 1776 (Coleoptera: Tenebrionidae), which are capable of digest that polymer. The goal of the present article was to analyze the behavior of T. molitor and Z. morio species as biodegradant agents of EPS. Both species were tested for hunger, using two control groups and two in the test, in which the control group was fed with wholemeal oatmeal and flour, potatoes and EPS, weighing the individuals and EPS of the four groups every 7 days. For the microbial test, the gut contents of the two individuals of both species were diluted in sterile distilled water for inoculation in growth medium. From the resulting colonies, the bacterias were isolated by the color difference and later inoculated into a carbon free basal medium containing an EPS film diluted in chloroform and dryed outdoor. As a result, it was observed that in the hunger test after 14 days there was a reduction in EPS weight for both species, from $3.62 \%$ reduction for the T. molitor and $3.01 \%$ for the $Z$. morio. In the microbial test only one colony, identified by the orange color, presented growth on the EPS film. It is possible to conclude that both species presented positive results of EPS degradation, besides the orange colony determined in the microbial test was obtained in the guts content of both presented interesting results of EPS degradation.
\end{abstract}

Keywords: Tenebrio molitor; Mealworm; Zophobas morio; Superworms; Styrofoam; Plastic degradation.

\section{Introdução}

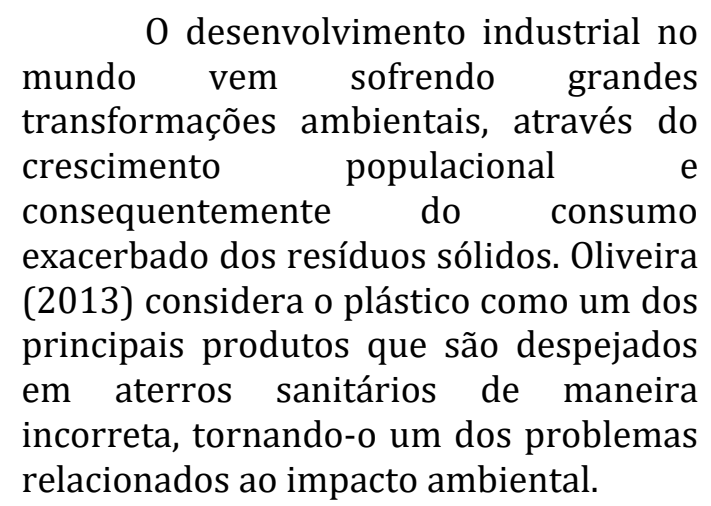

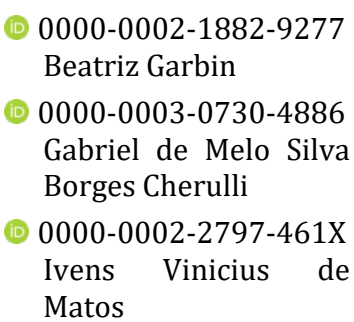


Uma maneira eficaz e limpa para o manejo do EPS é o uso da biotecnologia sendo uma ferramenta relevante de combate a impactos ambientais, visto que, por definição, refere-se à utilização de sistemas biológicos, organismos vivos ou derivados, a fim de criar ou modificar produtos e processos em usos específicos (Ferro, 2010).

A degradação do EPS depende das suas características e das condições ambientais, podendo variar conforme a exposição a fatores abióticos (sol, calor, umidade) ou pela assimilação dos microrganismos (fungos e bactérias) (Vinhas et al., 2007). Segundo Yang et al. (2015), um modo de degradar o EPS por microrganismos é pela decomposição biológica realizada pelas larvas de Tenebrio molitor e Zophobas morio.

No trato digestivo das espécies, ocorre a decomposição biológica, onde as bactérias conseguem decompor o EPS, transformando metade em dióxido de carbono e a outra metade em fragmentos decompostos em forma de excremento (Yang et al., 2015).

Dessa forma, diante da necessidade de estudos em relação à destinação correta do poliestireno, bem como sua degradação, o presente trabalho possui como objetivo analisar os comportamentos das espécies T. molitor e Z. morio como agentes biodegradantes do EPS.

\section{Material e métodos}

\section{Métodos para o teste de fome}

As larvas das espécies T. molitor e Z. morio (Figura 1) foram adquiridas no repositório de material biológico do laboratório de bioprocessos da Universidade Tecnológica Federal do Paraná, Campus Campo Mourão, Paraná, Brasil.
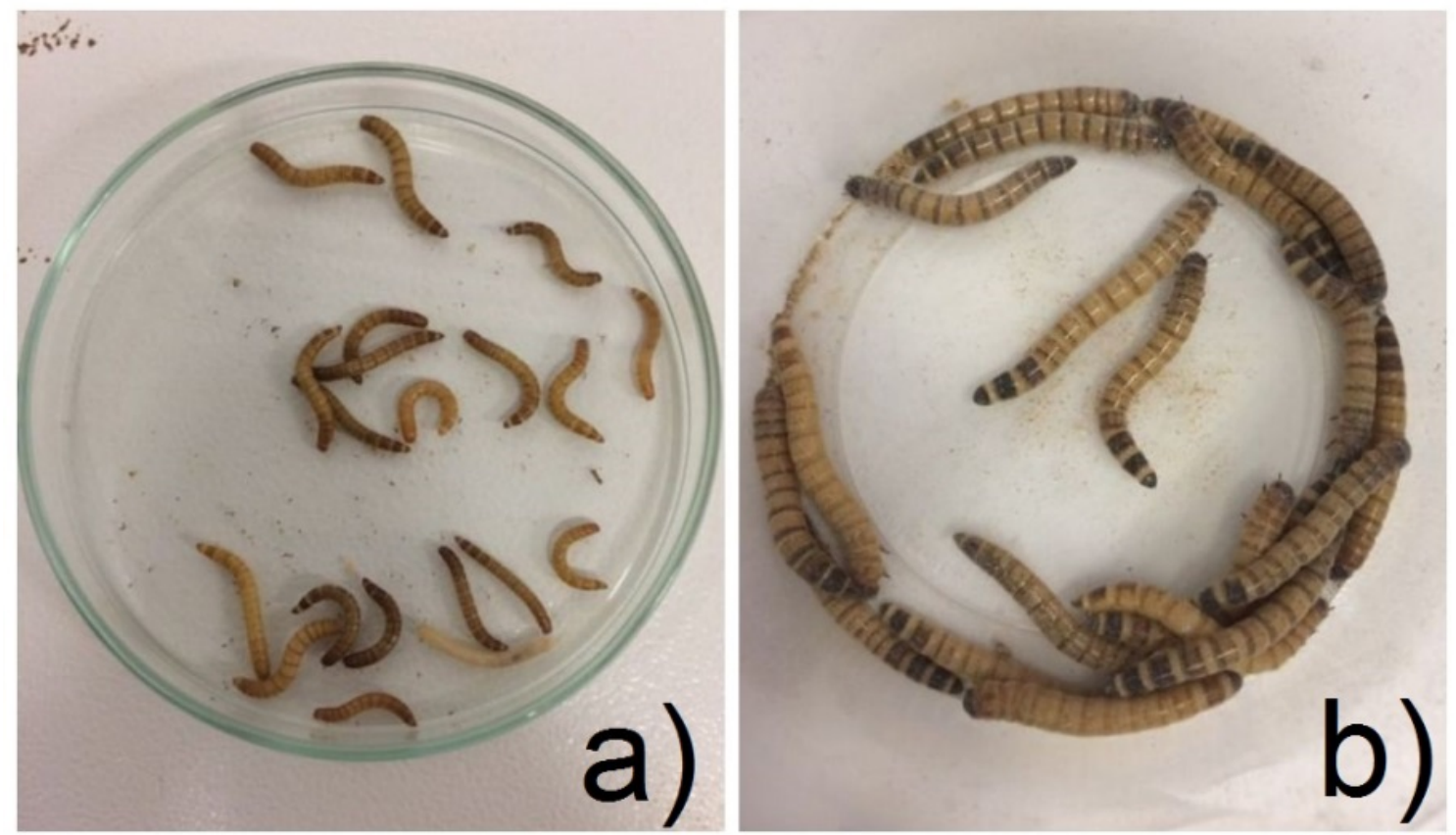

Figura 1. Agentes biodegradantes. Legenda: a) T. molitor e b) Z. morio. 
0 poliestireno expandido (EPS) apresentado na Figura 2 foi a base para a composição do substrato necessário para o desenvolvimento dos indivíduos. Foram construídos quatro recipientes para a execução do teste de fome $(15 \mathrm{~cm}$ $x 7,5 \mathrm{~cm})$. Destes quatro, dois constituem os recipientes de controle e os outros dois são testes, sendo um par para cada espécie.

O substrato que compõe o recipiente de controle é constituído por farinha integral, aveia integral, batata (Solanum tuberosum L.) e EPS granulado. O substrato do recipiente de teste é constituído exclusivamente por grânulos de EPS (Tabela 1).

Tabela 1. Composição dos substratos utilizados para o teste de fome das espécies Z. morio e T. molitor.

\begin{tabular}{|c|c|c|c|c|c|c|}
\hline & \multicolumn{4}{|c|}{ Substrato (g) } \\
\hline & & & $\mathbf{F}$ & A & $S$ & EPS \\
\hline \multirow{4}{*}{ 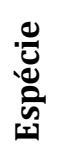 } & \multirow{2}{*}{ Z. morio } & $\mathbf{C}$ & 100,0216 & 50,0715 & 1,3444 & 1,3444 \\
\hline & & $\mathbf{T}$ & - & - & - & 3,3263 \\
\hline & \multirow{2}{*}{ T. molitor } & $\mathrm{C}$ & 100,0109 & 50,0829 & 1,3103 & 1,3103 \\
\hline & & $\mathbf{T}$ & - & - & - & 2,5915 \\
\hline
\end{tabular}

C- Controle; T- Teste; F- Farinha integral; A- Aveia integral; S- S. tuberosum; EPS: poliestireno expandido.

Foram introduzidos cinco indivíduos da espécie $Z$. morio no substrato controle e outros 5 no substrato teste. Da mesma forma, foram introduzidos 20 indivíduos da espécie T. molitor no segundo substrato controle e outros 20 no segundo substrato teste.

Todos os indivíduos foram previamente pesados individualmente e coletivamente. Também foram pesados a cada sete dias, para se obter a evolução dos pesos das populações e dos substratos de controle e de teste. Os recipientes foram reservados ao abrigo da luz direta e mantidos a $25^{\circ} \mathrm{C}$, até que se completasse o período de 28 dias. Os testes foram realizados entre os meses de agosto e novembro de 2017.

\section{microbiano \\ Métodos para o teste}

Para determinar a presença de bactérias biodegradantes de poliestireno no organismo das espécies, foram retirados o conteúdo estomacal de 2 indivíduos de cada espécie. Para isso, os indivíduos foram esterilizados em uma solução de etanol 70\% (v/v), dissecados e separados os tratos intestinais. Os indivíduos mantiveram uma dieta padrão do mesmo conteúdo apresentado no substrato de controle. Os conteúdos estomacais foram transferidos para dois recipientes contendo $30 \mathrm{~mL}$ de água destilada estéril, um para cada espécie.

As soluções foram então agitadas durante 5 min e inoculadas em placas de meio PCA por sete dias. Após este período, as colônias de colorações distintas foram inoculadas em placas de meio PCA específicas, com o objetivo de isolar as colônias observadas, também por sete dias. Ao final, as colônias que puderam ser isoladas foram transferidas para soluções de água peptonada, para posterior inoculação em meio ágar basal livre de carbono. Todo o processo de crescimento microbiano supracitado foi realizado a temperatura de $27^{\circ} \mathrm{C}$.

0 meio ágar basal livre de carbono (MABLC) foi preparado com água deionizada e contendo (por 1.000 mL) 0,7 g de $\mathrm{NH}_{4} \mathrm{NO}_{3}, 0,7$ g de $\mathrm{K}_{2} \mathrm{HPO}_{4}$, $0,7 \mathrm{~g}$ de $\mathrm{MgSO}_{4} \cdot 7 \mathrm{H}_{2} \mathrm{O}, 1,0 \mathrm{~g}$ de $\mathrm{NH}_{4} \mathrm{NO}_{3}$, 
0,005 g de $\mathrm{NaCl}, 0,002$ g de $\mathrm{FeSO}_{4} \cdot 7 \mathrm{H}_{2} \mathrm{O}$, 0,002 g de $\mathrm{ZnSO}_{4} \cdot 7 \mathrm{H}_{2} \mathrm{O}$, e $0,001 \mathrm{~g}$ de $\mathrm{MnSO}_{4} \cdot \mathrm{H}_{2} \mathrm{O}, 15 \mathrm{~g}$ de ágar-ágar, adaptado do padrão estabelecido pela ASTM para determinar a resistência de polímeros às bactérias (ASTM, 1996).

Para o preparo da película de EPS

(Figura 2) para a degradação microbiológica, dissolveu-se amostras de EPS em clorofórmio ([C]) em placas de Petri, o suficiente para que houvesse a formação de uma camada superficial do soluto que se dispersasse de forma contínua por toda a superfície das placas.

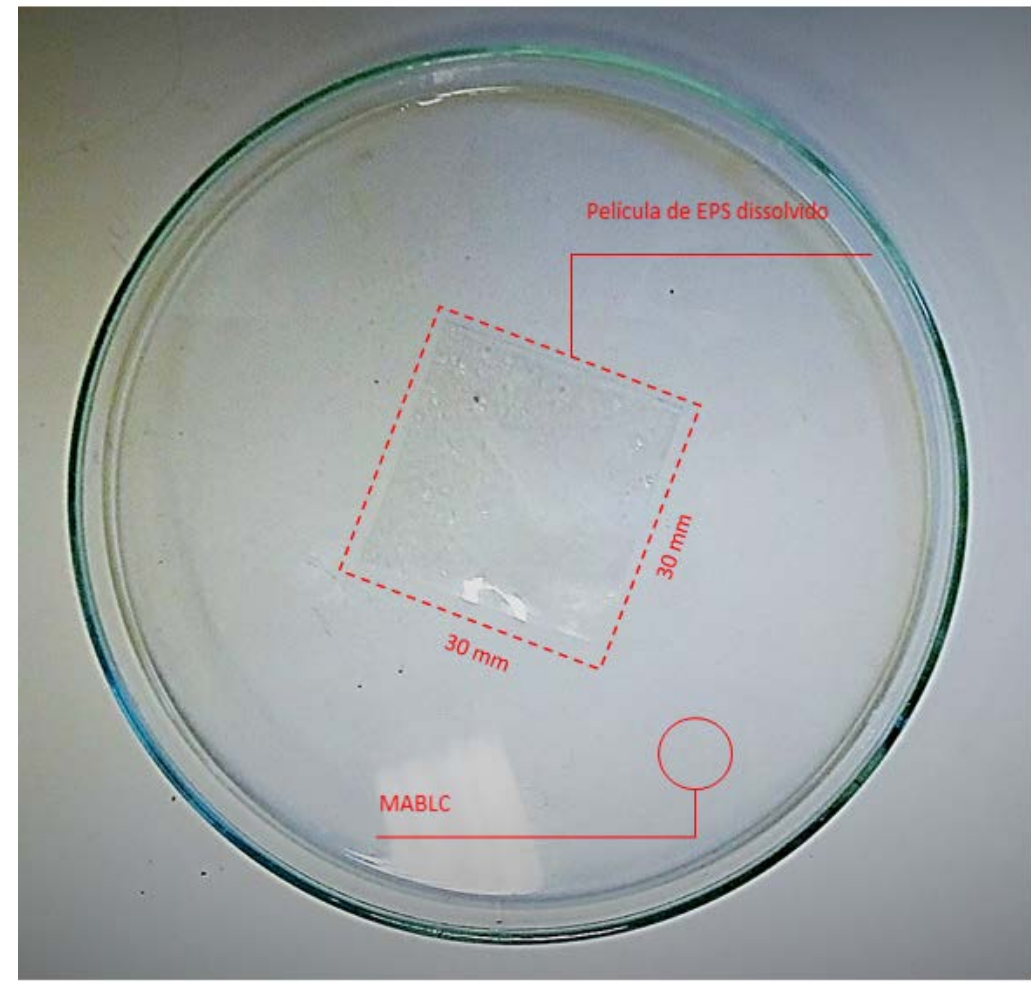

Figura 2. Película do EPS dissolvido. Fonte: Os autores.

A solução foi reservada em temperatura ambiente por 5 dias, para que ocorresse a evaporação do solvente. As películas de EPS resultantes tinham espessura de cerca de $0,02 \mathrm{~mm}$, e foram recortadas em peças quadradas de $30 \mathrm{x}$ $30 \mathrm{~mm}$. As películas foram imersas em solvente de metanol ([C]), lavadas com água deionizada e reservadas em local apropriado para a posterior introdução em meio ágar.

As películas foram introduzidas nas placas contendo MABLC, que receberam os inóculos pelo método "spread plate". As placas contendo as colônias isoladas inoculadas, as películas de EPS dissolvido e o MABLC, foram reservadas em estufa a $27{ }^{\circ} \mathrm{C}$ por 14 dias.

Após este período, foi analisada a formação de unidades formadoras de colônias (UFC) sobre as películas em contato com o MABLC.

\section{Resultados e discussão}

\section{Teste de fome}

Os indivíduos das espécies Z. morio e T. molitor foram monitorados em uma etapa de teste e outra de controle, utilizando na primeira o EPS como substrato restritivo e na segunda o 
substrato nutritivo (batata, aveia, farinha e EPS). Em ambas as etapas o período de observação foi de quatro semanas.
Os resultados da pesagem dos indivíduos e do substrato teste são representados a seguir na Figura 3.

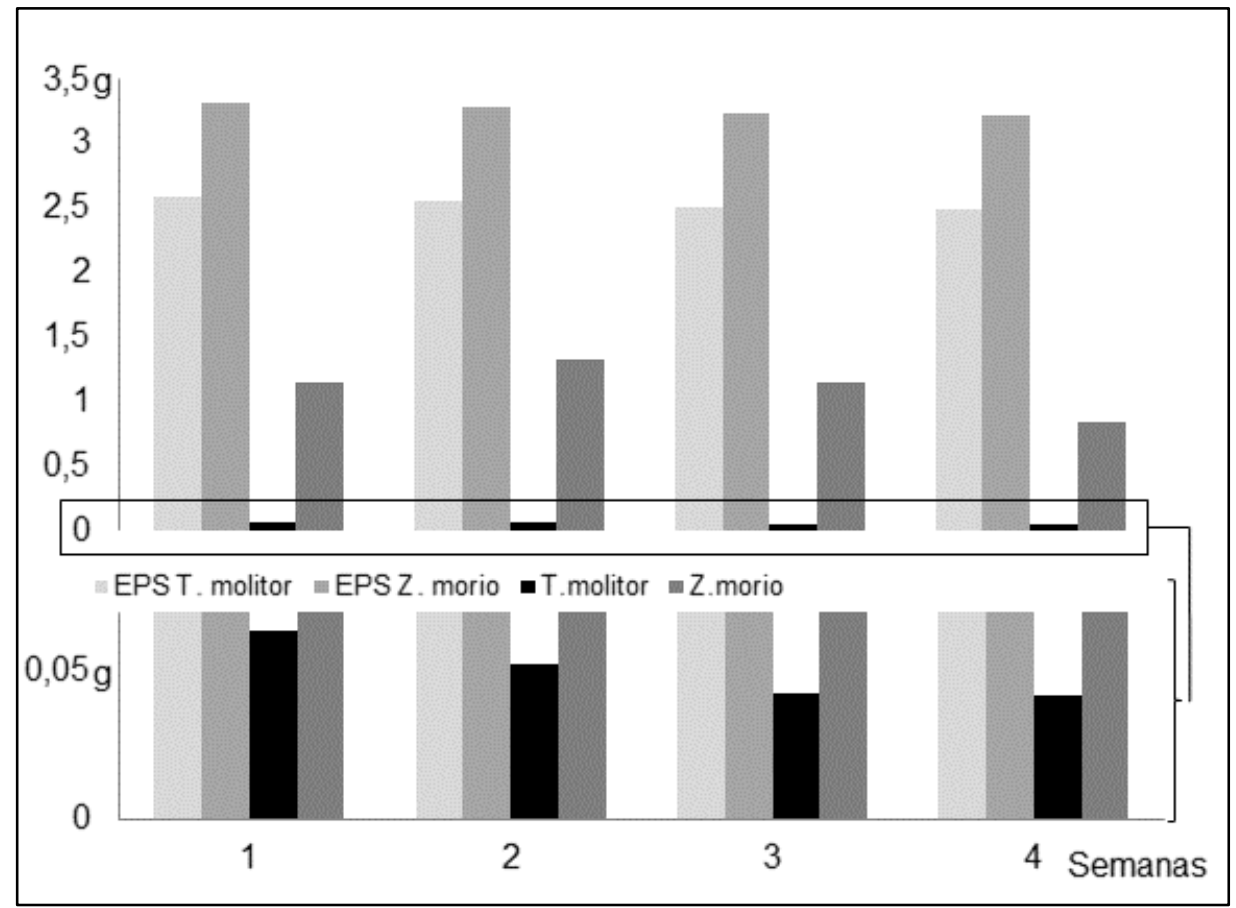

Figura 3. Relação dos pesos das espécies e do EPC. Fonte: Os autores.

Houve consumo do EPS por ambas as espécies, sendo as porcentagens de redução para $T$. molitor e Z. morio de 3,62 e 3,01\%, respectivamente. Verificou-se uma baixa redução do EPS, porém isso pode ser justificado pela quantidade de indivíduos inseridos no sistema da degradação do mesmo e também pelo tempo de experimento.

Yang et al. (2015) ao estudarem a degradação do EPS com 500 indivíduos de T. molitor no período de 30 dias, observaram uma redução entre $31,0 \pm$ $1,7 \%$, tendo uma massa inicial de 5,8 g. Os autores relatam que as mudanças da estrutura química, bem como da composição do EPS, ocorrem depois da passagem do mesmo pelo intestino.

Já a redução da massa por individuo da espécie T. molitor foi de $0,062 \%$ para Yang et al. (2015).
Comparado aos autores, os resultados do consumo do EPS nesse estudo tiveram uma melhor eficiência de redução, podendo estar relacionada à competição intraespecífica dos indivíduos.

Utilizando o substrato nutritivo (Figura 4), pode-se observar que o consumo foi notório em relação à etapa de teste. A redução para a espécie $T$. molitor foi de $32,28 \%$, já para a Z. morio foi de $33,01 \%$, esse aumento de consumo pode ser justificado pela perda de umidade dos componentes do substrato.

\section{Teste microbiano}

Na realização do teste microbiano para determinar a presença das bactérias biodegradantes do EPS, os conteúdos estomacais das espécies $T$. molitor e $Z$. morio foram transferidos para as placas dos meios PCA e BDA, após sete dias, 
verificou-se o crescimento de seis tipos de grupos de bactérias, identificadas por diferentes cores, sendo: amarelo, vermelho, ocre, transparente, branco e laranja (Tabela 2).

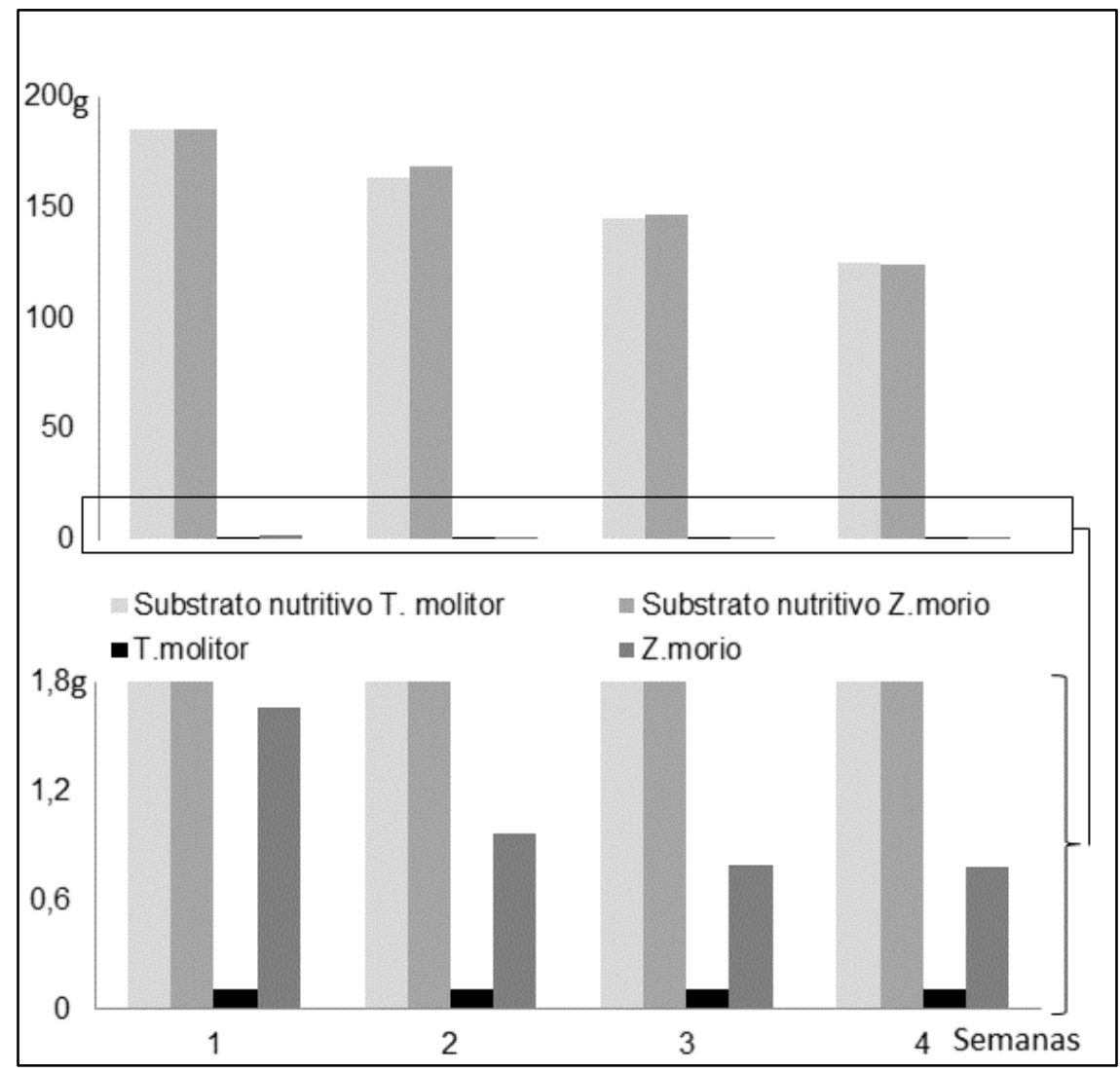

Figura 4. Relação dos pesos das espécies e do substrato nutritivo. Fonte: Os autores.

Tabela 2. Quadro de caracterização das colônias isoladas a partir do trato digestivo de Z. morio e T. molitor.

\begin{tabular}{|c|c|c|c|c|c|c|c|c|c|c|c|c|c|c|c|c|c|c|c|c|c|}
\hline & \multicolumn{9}{|c|}{ Z. morio } & \multicolumn{12}{|c|}{ T. molitor } \\
\hline Meio & \multicolumn{3}{|c|}{ BDA } & \multicolumn{6}{|c|}{ PCA } & \multicolumn{2}{|l|}{$\mathrm{BDA}$} & \multicolumn{10}{|c|}{ PCA } \\
\hline $\begin{array}{l}\text { Isolad } \\
\text { o }\end{array}$ & \multicolumn{3}{|c|}{$\mathrm{Vz}$} & \multicolumn{3}{|c|}{$\mathrm{Lz}$} & \multicolumn{3}{|c|}{$\mathrm{Bz}$} & \multicolumn{2}{|l|}{ Lt } & Lt & \multicolumn{3}{|c|}{$\mathrm{Tt}$} & \multicolumn{3}{|c|}{ At } & \multicolumn{3}{|c|}{ Ot } \\
\hline UFC & - & - & - & X & $X$ & - & - & - & - & - & - & & - & - & - & - & $\mathrm{X}$ & $\mathrm{X}$ & - & - & - \\
\hline
\end{tabular}

V - Vermelho; T - Transparente; B - Branco; L - Laranja; A - Amarelo; 0 - Ocre; z - bactérias isoladas a partir de Z. morio; $\mathrm{t}$ - bactérias isoladas a partir de T. molitor; X - presença de UFC.

Após a verificação desses resultados, as colônias caracterizadas pelas determinadas colorações, foram inoculadas em placas de MABLC em conjunto com as películas do EPS dissolvido, totalizando 24 placas. Após 14 dias, observou-se o crescimento bacteriano das espécies somente nas placas que continham as colônias de coloração laranja (Figura 5). 


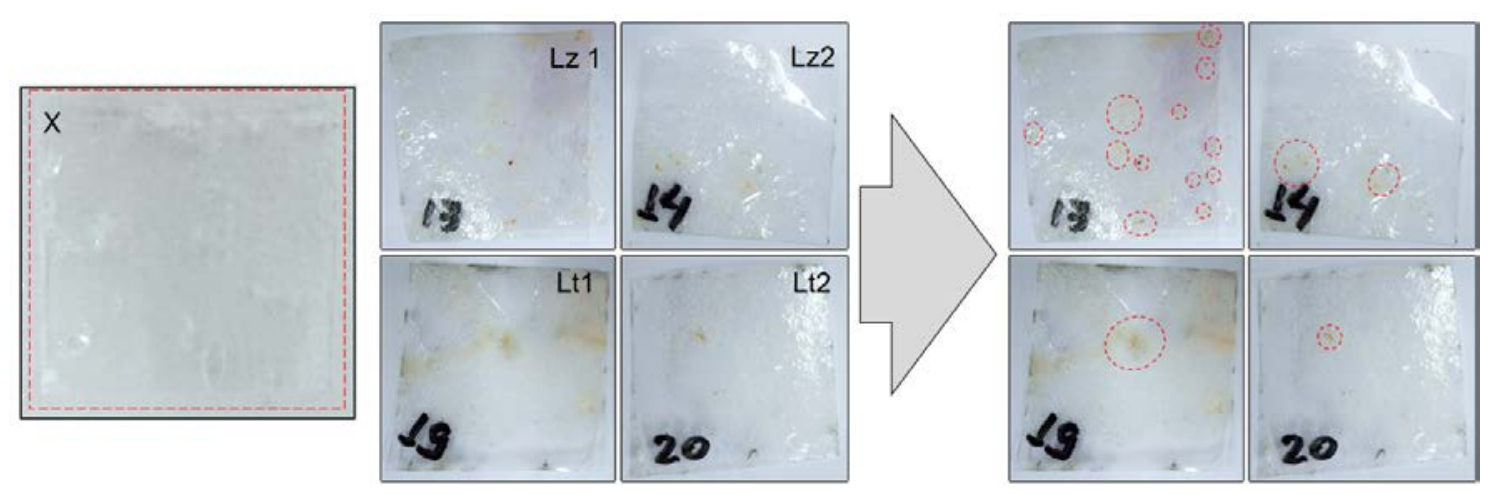

Figura 5. Bactérias biodegradantes de coloração laranja. Nota: X - Película genérica sem o crescimento microbiano. Lzx; Ltx - Pares de películas que apresentaram o crescimento microbiano de bactérias isoladas a partir do conteúdo presente no trato digestivo de Z. morio e T. molitor, respectivamente.

As bactérias encontradas a partir do teste microbiano apresentam aspectos similares, com a mesma coloração laranja da primeira geração de colônias isoladas nos meios BDA e PCA. Segundo Yang et al. (2015) o teste microbiano é de grande importância para a identificação dos microrganismos, uma vez que os mesmos produzem bactérias para a despolimerização e biodegradação de materiais como o EPS. Porém, há uma grande dificuldade em identificar as bactérias presentes no trato digestivo que realizam essa degradação dos materiais.

As bactérias presentes nos intestinos das larvas de T. molitor e Z. morio são as responsáveis pela a capacidade de digerirem o EPS, utilizam como fonte de energia para a degradação o carbono que foi convertido a $\mathrm{CO}_{2}$. Essa conversão é realizada a partir da ingestão do EPS pelas espécies que proporcionam a clivagem e a despolimerização das moléculas no mesmo (Yang et al., 2015).

Tang et al. (2017), utilizaram as espécies T. molitor e $Z$. morio na biodegradação do EPS e a partir do isolamento das bactérias, bem como da realização de análises laboratoriais (Turbidez, caracterização das bactérias,
TSI agar, etc.), os autores observaram a redução do EPS.

Ainda segundo o mesmo estudo, como resultado do teste microbiano os autores identificaram através do sequenciamento genético que as espécies sobreviventes ao EPS possivelmente foram Aeromonas taiwanensis, Aeromonas sanarellii, Aeromonas dhakensis, Aeromonas hydrophila ou Klebsiella pneumoniae.

\section{Conclusão}

Com base nos resultados obtidos no desenvolvimento deste trabalho e nos objetivos propostos, pode-se concluir que as espécies T. molitor e Z. morio no teste de fome apresentaram resultado positivo na biodegradação do EPS, tanto na etapa de teste, quanto na de controle. As eficiências de redução, utilizando somente o EPS como substrato, foi de $3,62 \%$ para a $T$. molitor e de $3,01 \%$ para a Z. morio. No substrato nutritivo, as eficiências foram de 32,28\% e 33,01\%, respectivamente.

No teste microbiano, houve crescimento de UFC's sobre a película de EPS dissolvido apenas nas placas que receberam o inóculo caracterizado pela cor laranja, indicando que tanto a espécie T. molitor quanto a Z. morio dispõem da 
mesma espécie de microorganismo com potencial biodegradante, já que o EPS constitui a única fonte de carbono para o desenvolvimento das colônias microbianas.

Em próximos estudos, deverá ser considerada a clonagem destas colônias isoladas para a replicação específica em meios restritivos, como o apresentado neste trabalho, possibilitando análises referentes à variação da integridade das películas de EPS ou outros polímeros.

\section{Declaração de conflito de Interesses}

Os autores declaram não haver conflito de interesses.

\section{Referências}

Boŝek, M.; Hanus-Lorenz, B.; Rybak, J. The studies on waste biodegradation by Tenebrio molitor. E3s Web of Conferences, v. 17, p. 1-7, 2017. https://doi.org/10.1051/ e3sconf/20171700011

Ferro, E.S. Biotecnologia translacional: hemopressina e outros peptídeos intracelulares. Estudos Avançados, v. 24, n. 70, p. 109-121, 2010. https://doi.org/ 10.1590/s0103-40142010000300008

Monteiro, M. A.; Silva, E. S.; Souza, J. G. Plano de gerenciamento integrado de resíduos de isopor - PGIRI. Belo Horizonte: Fundação Estadual do Meio Ambiente, 2011.

Oliveira, L.S. Reaproveitamento de resíduos de poliestireno expandido (isopor) em compósitos cimentícios. São João Del-Rei: Universidade Federal de São João Del-Rei, 2013. (Dissertação de mestrado).

Vinhas, G. M.; Almeida, Y. M. B.; Lima, M. A. G. A. Estudo das propriedades e biodegradabilidade de blendas de poliéster/amido submetidas ao ataque microbiano. Química Nova, v. 30, n. 7, p. 1584-1588, 2007. https://doi.org/10.1590/S0100-404220070 00700016

Tang, Z; Kuo, T; Liu, H. The study of the microbes degraded polystyrene. Advances in Technology Innovation, v. 2, n. 1, p. 13-17, 2017. Disponível em: <http://ojs.imeti.org/ index.php/AITI/article/view/204/324>. Acesso em: 23 ago. 2017.

Yang, Y.; Tang, J.; Wo, W.; Zhao, J.; Song, Y.; Gao, L.; Yang, R.; Jiang, L. Biodegration and mineralization of polystyrene by plastic eating meal: Part 1 . Chermical and physical characterzation and isotopic tests. Environmental Science and Tecnology, n. $49, \quad$ no. $20, \quad$ p. $12080-12086,2015$. https://doi.org/10.1021/acs.est.5b02661 